\title{
How Motivation Shapes the Sharing of Information Security Incident Experience
}

\author{
Muriel Frank \\ Goethe University Frankfurt \\ frank@wiwi.uni-frankfurt.de
}

\author{
Clara Ament \\ Goethe University Frankfurt \\ ament@wiwi.uni-frankfurt.de
}

\begin{abstract}
Due to a massive rise in data breaches caused by negligent information systems users, organizations aim at deploying measures that help make people more aware of potential cybersecurity risks. One means to raise security awareness amongst coworkers is sharing information security incident experience. Yet, many employees refrain from speaking up. Organizations, therefore, must understand what motivates their workforce to open up and share experiences. Empirical results based on a survey with 385 respondents indicate that intrinsic motivators like strengthening the collaboration with coworkers enhance employees' sharing behavior. In contrast, extrinsic motivators such as monetary incentives or promotion opportunities do the opposite. Interestingly, outcome expectations differ significantly for gender. Our results are of high relevance for practitioners, as understanding employees' security incident experience sharing behavior can help to properly incentivize individuals to communicate their incident experience and mitigate the likelihood of future information security breaches.
\end{abstract}

\section{Introduction}

Information security breaches have become a daily reality affecting large and small enterprises alike. A number of recent studies indicate that the majority of incidents is ascribable to human error [27, 57]. Employees might fall for phishing e-mails, download malware, send sensitive information, or transfer money [36, 71, 76]. Hence, technical solutions alone cannot secure an organizations' business anymore. Today's companies thus thrive heavily to employ security measures that prevent their employees from performing actions that might put organizational assets at risk [58, 68] and also help to learn from their colleagues' mistakes [31].

Following Tatu et al. [67], sharing information security incident experience works as a means to raise security awareness amongst coworkers as they gain both knowledge and expertise. It furthermore provides multiple learning opportunities, encourages coworkers to question certain behaviors, and helps to develop strategies and alter practices to prevent making the same mistakes again and again [1, 66, 67]. Information security awareness (ISA), in turn, is directly related to an employees' intention to comply with security rules and guidelines [15]. Hence, sharing incident experience can not only raise awareness about potential security risks but also promote information security policy compliance.

However, aside from legal requirements to notify customers and other parties about security breaches, employees are often very cautious when it comes to speaking up about incident experience and failures [26, $31,67]$. They might fear negative consequences for their status, self-image, or career [42]. Thus, it becomes crucial for organizations to understand what motivates individuals to help transform an episodic event into organizational knowledge and establish a culture of awareness and learning. Consequently, this study addresses the following research question:

$$
\begin{gathered}
\text { How do outcome expectations shape an } \\
\text { individuals' intention to share information security } \\
\text { incident experience? }
\end{gathered}
$$

To the best of our knowledge, we are the first to examine the relationship between motivational factors, information security incident experience sharing. By doing so, we can obtain a comprehensive understanding of an individuals' incident sharing behavior, which seems imperative for several reasons: First, current figures suggest that the likelihood of data breaches caused by negligent insiders is still increasing [57]. Second, through experience sharing individuals can gain important insights, which help increase their information security awareness $[1,67]$ and thus mitigate the probability of causing another data breach [61, 63]. Third, by understanding the role of outcome expectations, organizations are able to even better 
promote experience sharing initiatives and, in a broader sense, foster information security awareness.

This paper continues as follows: The next section provides the theoretical foundation for our research, first, surveying the literature on security awareness and motivation, including social cognitive theory and social exchange theory, and, second, deriving our research hypotheses. In section 3, we give details on our methodological procedure, the data collection, and the subsequent analysis. Section 4 presents the results of the empirical study with 385 employees. Section 5 discusses the contributions and limitations of this study, and section 6 eventually concludes.

\section{Theoretical background}

Nearly two decades ago, organizations began to realize that information security does not only depend on technical solutions but also on its users and their compliance with rules and regulations [74]. Ever since, they give attention to measures that would help train their employees' awareness of what actions can lead to better protection of information systems [15, 60]. Information security awareness is a basic understanding of security threats and risks and involves knowing how to react when encountering a security issue [74]. One promising approach is sharing incident experience because it helps to gain both knowledge and expertise $[1,31,67]$ and encourages employees to speak up and question certain behaviors eventually leading to higher awareness among the entire workforce [1].

This is in line with organizational theories saying that people can benefit from the experiences of others [7]. In everyday situations, plenty of opportunities occur in which one can either observe the behavior of others or is told about what others have experienced. The sharing of personal experience is part of many everyday conversations [54]. It serves as a means of sharing news, entertaining, and displaying ones' resistance to troubles. In an information security context, communicating incident experience acts as a social learning strategy as it helps employees gain new insights from their coworkers' previous experience with incidents [67]. In this study, we equate information security experience sharing with recapitulating unique experience obtained by direct exposure to a security incident and willingly sharing it. Sharing information security experience then results in joint ownership of a specific experience.

\subsection{Motivational orientation}

Motivation has been proven to significantly affect behavior, which is why it has become subject to investigations by researchers from various fields $[3,25$, $44,70]$. They have identified several classes of motivation, namely extrinsic and intrinsic motivation as well as amotivation, which influence the intentions of individuals [23, 28, 63]. While individuals are said to be extrinsically motivated when they perform a particular activity only when receiving some sort of external rewards, intrinsic motivation originates from inside the individuals [24]. Prior information systems research revealed that motivation exerts a significant influence on individuals' acceptance of new technologies [2, 23, $43]$ as well as their intentions to share knowledge [3, 18, 44]. With regard to information security, protection motivation theory and self-determination theory help to explain information security policy compliance and security misbehavior $[4,51,62]$; the impact of cognitive factors on information security incident sharing, however, remains unexplored.

According to social cognitive theory [8], most of the actions individuals perform are shaped by their expectations [18]. As a result, they preferably engage in behaviors that promise to be rewarded or lead to favorable outcomes than in undertaking behaviors that have unfavorable consequences $[8,20]$. Support for this notion comes from a study of knowledge sharing in virtual communities [18]. The authors show that personal and community-related outcome expectations shape the quantity as well as the quality of knowledge shared. Outcome expectations encompass building up one's reputation, strengthening collaboration, and feeling a sense of accomplishment. Community-related outcome expectations include, for instance, helping the company to grow and helping enrich the communities' knowledge base.

Paroutis and Al Saleh find individuals to engage in knowledge sharing when they feel their actions to be appreciated [56]. This is in line with social exchange theory [11], which posits that individuals interact with one another when expecting beneficial outcomes, such as social rewards. Social rewards comprise reputation, status, respect, and social image. Several studies confirm that individuals engage in knowledge sharing when perceiving that doing so is being approved by their peers, enhances their professional reputation, or helps them to present themselves in a positive light $[17,59$, 72].

For a long time, external incentives such as monetary rewards have been viewed as undermining intrinsic motivation and doing more harm than good [33, 75]. In recent years, however, this view has shifted. Researchers found evidence that extrinsic motivators can even have positive consequences $[16,32]$. Looking at knowledge sharing as the outcome of extrinsic motivation, Cabrera et al. find a positive relationship between extrinsic rewards and knowledge sharing [16]. In contrast, Bock et al. view rewards as detrimental to knowledge sharing [14]. 


\subsection{Hypotheses}

As no previous research has linked motivation, information security incident experience sharing behavior, and information security awareness, we draw from a combination of sources. Preliminary, we describe the motivators that seem to be of relevance for sharing incident experience, thereby building on social cognitive theory and social exchange theory. Where possible, we try to back up the proposed relationships between motivational factors, information security incident sharing, and security awareness with empirical research findings. We present our research model below (see Figure 1).

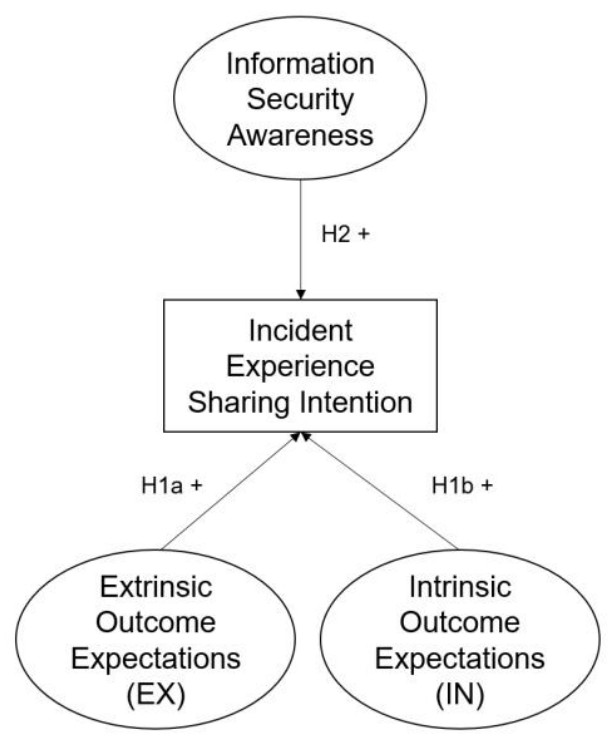

Figure 1. Research model

As employees' awareness about information security is a crucial task for organizations to successfully mitigate information security risks [63], understanding how to motivate them to share their incident experience becomes requisite. According to social cognitive theory, outcome expectations shape an individual's actions. Generally, this implies that people act in such a way that they believe that it will be rewarded [18]. Following Compeau and Higgins [20] and Chiu et al. [18], we expect employees to have various outcome-related expectations that shape their intention to share information security incident experience. We distinguish between extrinsic and intrinsic outcome expectations. Extrinsic outcome expectations refer to organizational incentives, such as bonus payments, promotions, and job security $[18,44]$. Intrinsic outcome expectations, however, encompass strengthening one's reputation, feeling a sense of accomplishment, and fostering collaboration with coworkers [18].

Intrinsic outcome expectations tend to have a positive effect on sharing initiatives [16]. For example, Anderson and Shirako acknowledge that an individuals' reputation is always related to a specific context; here the working context [5]. One way of developing a reputation is through interaction $[19,72]$. From this perspective, people share their incident experience because they expect that sharing will be valued by others, which in turn positively impacts their own reputation [67]. At the same time, they feel that by sharing their incident experience they prevent others from making the same mistakes de novo, which gives them a sense of accomplishment.

Findings regarding the impact of extrinsic motivators are opposing: Cabrera et al. find a moderate positive effect [17], while Bock et al. find such rewards to negatively affect knowledge sharing intentions [14]. Within social network sites, Zhao et al. find extrinsic motivators to work better with inactive members [77]. In an information security context, we expect extrinsic outcome expectations to have a positive impact on sharing incident stories because they convey the message that such behavior is valued and appreciated. Furthermore, we assume that chances for promotion, such as becoming a security ambassador, may increase the enjoyment of helping coworkers and raising security awareness. Increased job security may also increase employees' willingness to expand their coworkers' horizons, even at their own expense. That is because employees do not have to worry about being fired when causing a security breach [76] or evaluated by security adherence [5]. Having no extrinsic rewards for sharing in place, especially when employees come forward at their expenses, may spawn negative feelings. Building on the above, we hypothesize:

H1a: Extrinsic outcome expectations positively affect the intention to share information security incident experience.

H1b: Intrinsic outcome expectations positively affect the intention to share information security incident experience.

Extant research has confirmed that security awareness is one of the most important drivers of security behaviors [15, 41]. ISA, for instance, enhances information security policy compliance [15] and decreases information systems misuse [22]. That is because employees scoring high on security awareness tend to have a comprehensive understanding of security threats and, at best, are highly committed to their 
organization's security goals [15, 65]. Furthermore, they better understand how they could assist their coworkers [39, 41]. In a recent field study, Jaeger and Eckhardt showed that security-aware employees are more likely to support less capable coworkers in protecting organizational assets [41]. Hence, we expect employees with higher information security awareness to share their incident experience because they understand that sharing helps their colleagues to better assess potential information security threats. As a result, overall security awareness increases:

$\mathrm{H} 2$ : Information security awareness is positively related to the intention to share information security incident experience.

\section{Methodology}

Here, we provide details on the data collection procedure, the sample characteristics, and the employed research measures. To examine whether extrinsic and intrinsic outcome expectations influence the information security experience sharing behavior of individuals, we collected survey data of 385 employees whom we recruited from a large online labor market. To test this relationship, we built a structural model.

\subsection{Data collection}

We surveyed 385 employees from a subject pool of a large online labor market in Germany. Accessing online labor markets to recruit participants is widely accepted in scientific research [55], as the data obtained from these samples turns out to be both internally and externally valid [10]. Moreover, studies show that respondents from online labor markets are usually even more diverse than student or internet samples [14, 37].

In order to examine the impact of motivational orientation on experience sharing behavior of employees, we filtered out all subjects who are currently not employed. Implanting an additional sentry, we measured the time respondents needed for survey completion and removed all data sets with an unduly low duration. As proposed by Lowry et al. [45], rewards for completing the survey were roughly equivalent to minimum wages in Germany. To affirm the accuracy of responses, we randomly used reverse-coded questions [45]. After having applied the controls, a total of 348 out of the collected 385 were kept for analysis.

Table 1 portrays the sample demographics. $56.9 \%$ of the participants were males. The respondents' age ranged from 18 for the youngest to 70 for the oldest, leading to an average of 38.0 years. Except for one, all of the participants graduated at least from high school. More than half of them have a university degree, which points to a relatively high education level. Apart from that, most of the respondents are employees with a working experience of more than 15 years. Participants spread almost evenly over all industries, with most of them belonging to the IT-sector (13.5\%), financial services $(12.6 \%)$, and education $(9.8 \%)$.

Table 1. Sample characteristics

\begin{tabular}{|c|c|}
\hline \multicolumn{2}{|l|}{ Gender } \\
\hline Male & 198 (56.9\%) \\
\hline Female & 148 (42.5\%) \\
\hline Diverse & $2(0.6 \%)$ \\
\hline \multicolumn{2}{|l|}{ Position } \\
\hline $\begin{array}{r}\text { Employees (without managing } \\
\text { responsibilities) }\end{array}$ & 261 (75.0\%) \\
\hline Department Manager & $28(8.0 \%)$ \\
\hline Managing Director & $21(6.0 \%)$ \\
\hline Others & 38 (10.9\%) \\
\hline \multicolumn{2}{|l|}{ Educational Level } \\
\hline University Degree & $180(51.7 \%)$ \\
\hline No University Degree & 168 (48.3\%) \\
\hline
\end{tabular}

\subsection{Measurement}

To measure the different constructs, we draw on existing scales and adjusted them to fit the information security experience sharing context. Table 2 provides an overview of the used items.

Extrinsic outcome expectations. We utilized the expected organizational scale from Lin [44], which included expectations of promotion, job security, or monetary incentives. Respondents rated how much they agreed with each of the items on a 5-point Likert scale ranging from 1 ("strongly disagree") to 5 ("strongly agree").

Intrinsic outcome expectations. We adapted the outcome expectations scale of Chiu et al. [18] to assess the level of intrinsic motivation. It entails reputation, a sense of accomplishment, and better cooperation between coworkers. Again, we asked respondents to rate the items on a 5-point Likert scale ranging from 1 ("strongly disagree") to 5 ("strongly agree").

Sharing intention. Assessing whether participants are willing to share their information security incident experience, we asked them to rate their sharing intention on a scale ranging from 1 ("strongly disagree") to 5 ("strongly agree"). Measuring the intention of performing actions is widely accepted in information systems research, as intentions are a good predictor of individuals' actual behavior [29]. Besides, several studies with regard to information security have proven that intention and behavior are closely related [15]. 
Information security awareness. We used the general information security awareness scale of Bulgurcu et al. [15] to assess whether participants perceive to have sufficient knowledge about potential security risks.

Demographic information. Participants were asked to report their age in years and their highest level of education. We also asked them to report on the average time of daily IT use and their working experience (in years). Furthermore, respondents stated if a security incident has ever happened to them.

Table 2. List of items

\begin{tabular}{|c|c|c|}
\hline \multirow{3}{*}{ 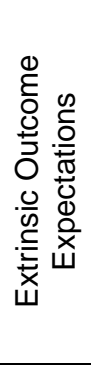 } & ex1 & $\begin{array}{l}\text { I will receive a higher bonus in } \\
\text { return for sharing my information } \\
\text { security incident experience. }\end{array}$ \\
\hline & ex2 & $\begin{array}{l}\text { I will receive increased promotion } \\
\text { opportunities in return for sharing } \\
\text { my information security incident } \\
\text { experience. }\end{array}$ \\
\hline & ex3 & $\begin{array}{l}\text { I will receive increased job security } \\
\text { in return for sharing my information } \\
\text { security incident experience. }\end{array}$ \\
\hline \multirow{3}{*}{ 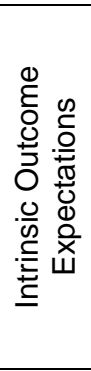 } & in1 & $\begin{array}{l}\text { Sharing my information security } \\
\text { incident experience can build up my } \\
\text { reputation. }\end{array}$ \\
\hline & in2 & $\begin{array}{l}\text { Sharing my information security } \\
\text { incident experience will give me a } \\
\text { sense of accomplishment. }\end{array}$ \\
\hline & in3 & $\begin{array}{l}\text { Sharing my information security } \\
\text { incident experience will enable me } \\
\text { to gain better cooperation with my } \\
\text { coworkers. }\end{array}$ \\
\hline \multirow{3}{*}{ 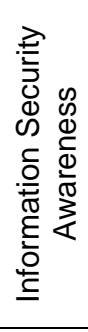 } & isa1 & $\begin{array}{l}\text { Overall, I am aware of the potential } \\
\text { security threats and their negative } \\
\text { consequences. }\end{array}$ \\
\hline & isa2 & $\begin{array}{l}\text { I understand the concerns } \\
\text { regarding information security and } \\
\text { the risks they pose in general. }\end{array}$ \\
\hline & isa3 & $\begin{array}{l}\text { I have sufficient knowledge about } \\
\text { the cost of potential security } \\
\text { problems. }\end{array}$ \\
\hline 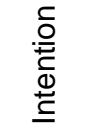 & int & $\begin{array}{l}\text { I will share my information security } \\
\text { incident experience with my } \\
\text { colleagues. }\end{array}$ \\
\hline
\end{tabular}

\section{Results}

Executing IBM SPSS Statistics 27, we first checked the reliability of our constructs. All factors except for security awareness showed a Cronbach's alpha above 0.8 , which is good [21]. Hence, we took a closer look at ISA and eliminated one item (isa3) for an increase of Cronbach's alpha to 0.822 . Afterward, we performed an exploratory factor analysis (EFA). An EFA allows the validation of the constructs [73]. We used maximum likelihood for our extraction method. KMO (0.746) and Bartlett's Test of Sphericity revealed sampling adequacy. Factor loadings of the items sat above the recommended minimum value of 0.4 [35]. We also checked for composite reliability, which was above the threshold of 0.7 [30] for all constructs. The average variance extracted (AVE) was above 0.5 for all latent constructs. To further investigate our constructs' discriminant validity, we applied the Fornell-Larcker criterion and compared the square root of the AVE with the correlations between constructs - we found no validity issues.

Next, we conducted a confirmatory factor analysis (CFA) to approve the structure identified in the EFA. For conducting the CFA, we ran SPSS Amos 27. To control for common method bias [47], we used a common latent factor (CLF). For large differences in regression weights for the model with and without CLF, we retained CLF as we moved on with structural equation modeling to diagnose the relationship of expectations, information security incident experience sharing, as well as security awareness. Extrinsic and intrinsic motivators are supposed to relate to one's intention to share personal information security incident experience, which, in turn, shall affect information security awareness. To test this relationship, we built a structural model. Comparing the model fit indices against the recommended thresholds $[35,40]$ confirmed the model's excellent fit (see Table 3).

Table 3. Fit indices of the research model

\begin{tabular}{|l|l|}
\hline Fit Index & $\begin{array}{l}\text { Model Characteristics (Acceptable } \\
\text { Threshold[35]) }\end{array}$ \\
\hline $\mathrm{X}^{2} / \mathrm{df}$ & $1.795(<3.00)$ \\
\hline $\mathrm{CFI}$ & $0.969(>0.92)$ \\
\hline TLI & $0.958(>0.92)$ \\
\hline RMSEA & $0.048($ if $\mathrm{CFI}>0.92:<0.07)$ \\
\hline SRMR & $0.057($ if $\mathrm{CFI}>0.92:<0.08)$ \\
\hline
\end{tabular}

All of the proposed paths are significant (see Figure 2). Thereby, the model confirms our expectation that extrinsic and intrinsic outcome expectations affect one's intention to share information security incident experience. Specifically, intrinsic motivators work better to enhance incident experience sharing than extrinsic motivators like monetary incentives. Interestingly, gender has a significant effect on both extrinsic and intrinsic motivation. The educational level of participants just significantly affects extrinsic but not intrinsic outcome expectations. We find no age effects with regard to extrinsic and intrinsic motivators, respectively.

To test whether prior incident experience impacts the relationship between outcome expectations and 
sharing intention, we performed a group analysis. We find that the negative relationship between extrinsic outcome expectations and experience sharing is stronger for those with no prior incident experience (-0.14 vs. $-0.22 ; p<0.027)$. No group differences were found for the path between intrinsic outcome expectations and sharing intentions.

\section{Discussion}

The purpose of this research is to gain a greater understanding of what motivates individuals to share information security incident experiences with coworkers. With reference to our research question, we surveyed 385 participants and found that particular kinds of motivation can enhance the sharing of information security incident experience. As a result, this study provides important contributions to theory as we present detailed empirical findings on how outcome expectations influence an individuals' intention to share experience about security incidents. Besides, our work provides practitioners with new insights on how to raise information security awareness amongst employees. Our final sections will discuss implications for information security researchers and practitioners as well as limitations and future research endeavors.

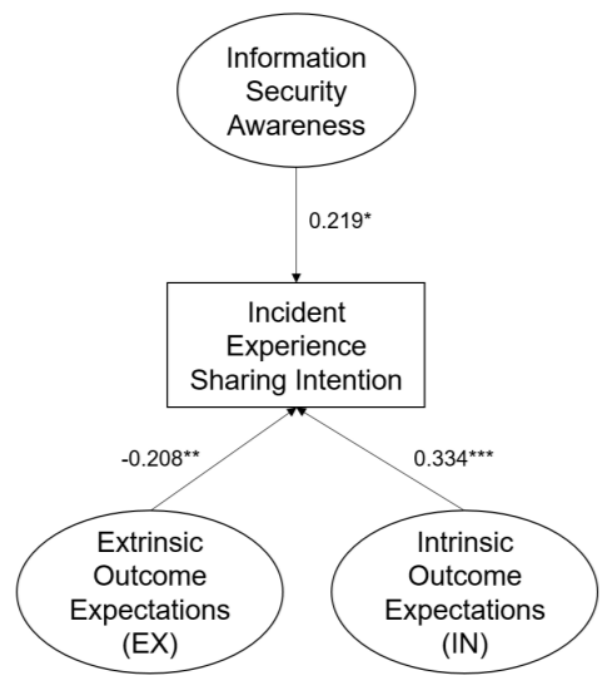

Controls:

gender $\rightarrow$ EX $-0.213^{\star \star \star}$; gender $\rightarrow \mathrm{IN}-0.246^{\star \star \star}$; age $\rightarrow$ EX 0.024 ; age $\rightarrow$ IN 0.025 ; education $\rightarrow$ EX $-0.135^{*}$; education $\rightarrow$ IN -0.066

Significance Level: ${ }^{\star \star \star} p<0.001 ;{ }^{\star \star} p<0.010 ;{ }^{\star} p<0.050$

Figure 2. Research results

\subsection{Contributions and implications}

To our knowledge, we are the first to delineate that extrinsic and intrinsic outcome expectations significantly influence an individual's intention to share information security incident experience. Ergo, our work adds to the emerging body of research that highlights the impact of individualistic traits in the information security context [49, 64, 69]. Furthermore, it provides support for the social cognitive theory perspective on information security experience sharing.

The effect of intrinsic outcome expectations on information security incident experience sharing is as expected: When incentivized by intrinsic motivators, people tend to share more. As stated above, this is in line with findings from the field of knowledge management. Wasko and Faraj, for instance, find individuals who wish to enhance their reputation to share knowledge in online networks [72]. Cheung and Lee furnish additional evidence that reputation is a strong motivator for consumers to engage more in knowledge sharing activities [17]. This is in line with the reputation enhancement theory suggesting that individuals develop, maintain, and protect the image they wish others to have of them [19]. One way of managing one's impression is by what one tells other people [19]. From this perspective, employees would decide to share their experience because they feel doing so will present themselves in a favorable light [67].

Opposed to our expectations, individuals will share less information security incident experience when incentivized by extrinsic motivators. One possibility is that even expected promotion or bonus opportunities cannot rule out their fear of negative consequences when sharing information security incident experience with their coworkers, especially when responsible for the incident. This corresponds with findings by Michailova and Husted [52], who examined the knowledge sharing behavior of Russian employees and revealed that sharing could backfire and put jobs in jeopardy. We assume extrinsic rewards might rule out the intrinsic motivation to help others. Evidence is provided by Guhr et al. [34], who suggest that incentivizing individuals who are not motivated to behave in a certain way may rebound. Instead of motivating unwilling employees, extrinsic rewards may supersede their intrinsic motivation and undermine their enjoyment in helping workmates [75].

The level of security awareness plays a significant role for sharing incident experience. The more aware employees are, the higher their intention to share an incident experience. Support comes from Jaeger and Eckhardt [41], who state that conscious employees have a better understanding of how to aid their colleagues in security matters.

Another absorbing finding is that gender relates negatively to outcome expectations, meaning that women respond less to either kind of motivation. This is contrary to social role theory, positing that women 
typically focus on cooperation while men act openly competitive [46]. In the information security context, we find female workers to not respond to intrinsic outcome expectations like cooperation. Sharing incident experience seems to be something they do not value intrinsically. One explanation comes with research suggesting that men performing male-oriented tasks rather ask for feedback [53]. Since information security is traditionally considered a male-oriented domain [50], men might more likely share information security experience, ask their peers for feedback, and strengthen cooperation. Besides, first studies in the field of information security reveal gender differences. Anwar et al., for instance, examine the relationship between gender and information security beliefs and behavior [6]. Their results indicate that women report lower levels of self-efficacy than men, which might be a reason for not being motivated to share their incident experience.

The educational level is also negatively linked to motivation; however, only the path from education to extrinsic outcome expectations is significant, meaning that adults with higher educational levels will respond less to extrinsic outcome expectations. It seems that high-skilled participants feel that incentives like bonuses and promotion opportunities are not necessary.

Some practical implications can be drawn from our findings and provide information security practitioners with some guidelines for sharing strategies. First, we advise organizations to mind individual differences regarding incident experience sharing. This may be principally reasonable, as preceding research has revealed that experience sharing helps increase information security awareness among coworkers [67], which mitigates the risk of becoming a victim of cybercriminals. Besides this, sharing insights helps develop and adjust activities to prevent others from making the same mistakes $[66,67]$.

Second, we suggest organizations reflect particular extrinsic reward systems when developing sharing initiatives as employees are more willing to engage in experience sharing when not incentivized by extrinsic motivational factors.

Third, information security experience sharing creates value for organizations by helping their employees resolve a problem or protect themselves against cyberattacks. We highly advise organizations to collect such stories, as incident experience provides an excellent learning opportunity [7, 9, 12]. Narratives about other people's information security experience could function as a promoter for avoiding making the same mistakes de novo. Organizations could provide their employees with a platform on which they can share learning situations.
Forth, in order to raise security awareness among the entire workforce, managers in charge may want to identify employees who already have higher security awareness and assess whether they are extraordinarily interested in information security. If so, they could be assigned to a mentoring program [41].

\subsection{Limitations and future research}

Despite our contributions, some limitations should be acknowledged. First, this study is the first to test the relationship between motivation, information security incident experience, and awareness. Therewith, reexamination is needed. Second, we only focus on a few motivational factors as determinants of information security sharing behavior. Other behavioral elements might play a role but are not considered here. A subsequent study may integrate hedonism, reciprocity, obligation, or subjective norms, which may also work as motivators in the context of information security experience sharing. Another limitation is that this study was conducted in a particular culture. Testing across various cultures may clarify whether our results differ across countries and, thus, improve the external validity of our results.

Another promising research approach is to use longitudinal data to examine whether our findings are stable over time. Further studies could also analyze the costs associated with revealing security failures to coworkers. Such research will help to understand why employees refrain from sharing experience. Taking their employees' personalities into account would also of interest for companies who wish to advance experience sharing initiatives. Then they would have the chance to compose working units according to their employees' personalities [48]. The selection of employees could be based upon self-reports. Organizations can foster experience sharing by recognizing the personality of their employees and pick those who actively engage in experience sharing. This might encourage others to follow, as we know from previous research how important role models are for motivation [38].

\section{Conclusion}

Our work is the earliest to empirically investigate how motivational factors influence an individuals' intention to share information security incident experience. With data collected from a large online labor market, this study unveils that extrinsic and intrinsic outcome expectations can either inhibit or promote the sharing of incident experience, thereby providing a perspective for practitioners who try to increase information security awareness through sharing initiatives. Besides, we find motivational factors 
to work differently for male and female workers. Hence, organizations desiring to secure their information systems must be gender-aware. Otherwise, they will fail to develop strategies that raise their workforce's security awareness level and may also fail to prevent their employees from making the same mistakes all over again.

\section{References}

[1] Albrechtsen, E. and J. Hovden, "Improving information security awareness and behaviour through dialogue, participation and collective reflection. An intervention study", Computers \& Security, 29(4), 2010, pp. 432-445.

[2] Allam, H., M. Bliemel, L. Spiteri, J. Blustein, and H. AliHassan, "Applying a multi-dimensional hedonic concept of intrinsic motivation on social tagging tools: A theoretical model and empirical validation", International Journal of Information Management, 45, 2019, pp. 211-222.

[3] Almeida, F.C. de, H. Lesca, and A.W.P. Canton, "Intrinsic motivation for knowledge sharing - competitive intelligence process in a telecom company", Journal of Knowledge Management, 20(6), 2016, pp. 1282-1301.

[4] Alzahrani, A., C. Johnson, and S. Altamimi, "Information security policy compliance: Investigating the role of intrinsic motivation towards policy compliance in the organisation", 4th International Conference on Information Management, 2018, pp. 125-132.

[5] Anderson, C. and A. Shirako, "Are Individuals' Reputations Related to Their History of Behavior?", Journal of Personality and Social Psychology, 94(2), 2008, pp. 320 333.

[6] Anwar, M., W. He, I. Ash, X. Yuan, L. Li, and L. Xu, "Gender difference and employees' cybersecurity behaviors", Computers in Human Behavior, 69, 2017, pp. 437-443.

[7] Bandura, A., Social Learning Theory, Prentice-Hall, Englewood Cliffs, NJ, US, 1977.

[8] Bandura, A., Social Foundations of Thought and Action: A Social Cognitive Theory, Prentice-Hall, 1986.

[9] Bauer, J. and R.H. Mulder, "Modelling learning from errors in daily work", Learning in Health and Social Care, 6(3), 2007, 121-133.

[10] Berinsky, A.J., G.A. Huber, and G.S. Lenz, "Evaluating Online Labor Markets for Experimental Research: Amazon.com's Mechanical Turk", Political Analysis, 20(3), 2012, pp. 351-368.

[11] Blau, P.M., Exchange and Power in Social Life, Wiley, New York, NY, US, 1964.

[12] Bledow, R., B. Carette, J. Kühnel, and D. Bister, "Learning From Others' Failures: The Effectiveness of Failure Stories for Managerial Learning", Academy of Management Learning \& Education, 16(1), 2017, pp. 39-53.
[13] Bock, G.-W., J.-N. Lee, R.W. Zmud, and Y.-G. Kim, "Behavioral Intention Formation in Knowledge Sharing: Examining the Roles of Extrinsic Motivators, SocialPsychological Forces, and Organizational Climate", MIS Quarterly, 29(1), 2005, pp. 87-111.

[14] Buhrmester, M., T. Kwang, and S.D. Gosling, "Amazon's Mechanical Turk: A New Source of Inexpensive, Yet HighQuality, Data?", Perspectives on Psychological Science, 6(1), 2011, pp. 3-5.

[15] Bulgurcu, B., H. Cavusoglu, and I. Benbasat, "Information Security Policy Compliance: An Empirical Study of Rationality-Based Beliefs and Information Security Awareness", MIS Quarterly, 34(3), 2010, pp. 523-548.

[16] Cabrera, Á., W.C. Collins, and J.F. Salgado, "Determinants of individual engagement in knowledge sharing", The International Journal of Human Resource Management, 17(2), 2006, pp. 245-264.

[17] Cheung, C.M.K. and M.K.O. Lee, "What drives consumers to spread electronic word of mouth in online consumer-opinion platforms", Decision Support Systems, 53(1), 2012, pp. 218-225.

[18] Chiu, C.-M., M.-H. Hsu, and E.T.G. Wang, "Understanding knowledge sharing in virtual communities: An integration of social capital and social cognitive theories", Decision Support Systems, 42(3), 2006, pp. 1872-1888.

[19] Chong, D., "Reputation and cooperative behavior", Social Science Information, 31(4), 1992, pp. 683-709.

[20] Compeau, D.R. and C.A. Higgins, "Computer SelfEfficacy: Development of a Measure and Initial Test", MIS Quarterly, 19(2), 1995, pp. 189-211.

[21] Cortina, J.M., "What Is Coefficient Alpha? An Examination of Theory and Applications", Journal of Applied Psychology, 78(1), 1993, pp. 98-104.

[22] D'Arcy, J., A. Hovav, and D. Galletta, "User Awareness of Security Countermeasures and Its Impact on Information Systems Misuse: A Deterrence Approach", Information Systems Research, 20(1), 2009, pp. 79-98.

[23] Davis, F.D., R.P. Bagozzi, and P.R. Warshaw, "Extrinsic and Intrinsic Motivation to Use Computers in the Workplace", Journal of Applied Social Psychology, 22(14), 1992, pp. 1111-1132.

[24] Deci, E.L., "Effects of Externally Mediated Rewards on Intrinsic Motivation", Journal of Personality and Social Psychology, 18(1), 1971, pp. 105-115.

[25] Deci, E.L. and R.M. Ryan, "The Support of Autonomy and the Control of Behavior", Journal of Personality and Social Psychology, 53(6), 1987, pp. 1024-1037.

[26] Edmondson, A.C., Teaming: How Organizations Learn, Innovate, and Compete in the Knowledge Economy, JosseyBass, 2012.

[27] Evans, M., Y. He, L. Maglaras, and H. Janicke, "HEARTIS: A novel technique for evaluating human error-related 
information security incidents", Computers \& Security, 80, 2019, pp. 74-89.

[28] Fagan, M.H., S. Neill, and B. Ross Wooldridge, "Exploring the Intention to Use Computers: An Empirical Investigation of the Role of Intrinsic Motivation, Extrinsic Motivation, and Perceived Ease of Use", Journal of Computer Information Systems, 2008, pp. 31-37.

[29] Fishbein, M.A. and I. Azjen, Belief, attitude, intention and behaviour: An introduction to theory and research, Reading MA: Addison-Wesley, 1975.

[30] Fornell, C. and D.F. Larcker, "Evaluating Structural Equation Models with Unobservable Variables and Measurement Error", Journal of Marketing Research, 18(1), 1981, pp. 39-50.

[31] Frank, M., "Sharing Information Security Failure: The Role of Social Context and Social Environment", in Proceedings of the 24th Pacific Asian Conference on Information Systems, D. Vogel, C.N. Shen, and P.S. Ling, Editors. 2020.

[32] Gagné, M. and E.L. Deci, "Self-determination theory and work motivation", Journal of Organizational Behavior, 26(4), 2005, pp. 331-362.

[33] Gerhart, B. and M. Fang, "Pay, Intrinsic Motivation, Extrinsic Motivation, Performance, and Creativity in the Workplace: Revisiting Long-Held Beliefs", Annual Review of Organizational Psychology and Organizational Behavior, 2(1), 2015, pp. 489-521.

[34] Guhr, N., B. Lebek, and M.H. Breitner, "The impact of leadership on employees' intended information security behaviour: An examination of the full-range leadership theory", Information Systems Journal, 29(2), 2019, pp. 340362 .

[35] Hair, J.F., B.J. Babin, R.E. Anderson, and W.C. Black, Multivariate Data Analysis, Pearson Education Limited, Harlow, Essex, 2014.

[36] Holmes, A., "Hackers are getting better at tricking people into handing over passwords - here's what to look out for according to experts", Business Insider, 02/24/2020.

[37] Horton, J.J., D.G. Rand, and R.J. Zeckhauser, "The Online Laboratory: Conducting Experiments in a Real Labor Market", Experimental Economics, 14(3), 2011, pp. 399-425.

[38] Hoyt, C.L., J.L. Burnette, and A.N. Innella, "I Can Do That: The Impact of Implicit Theories on Leadership Role Model Effectiveness", Personality \& Social Psychology Bulletin, 38(2), 2012, pp. 257-268.

[39] Hsu, J.S.-C., S.-P. Shih, Y.W. Hung, and P.B. Lowry, "The Role of Extra-Role Behaviors and Social Controls in Information Security Policy Effectiveness", Information Systems Research, 26(2), 2015, pp. 282-300.

[40] Hu, L.-t. and P.M. Bentler, "Cutoff criteria for fit indexes in covariance structure analysis: Conventional criteria versus new alternatives", Structural Equation Modeling: A Multidisciplinary Journal, 6(1), 1999, pp. 1-55.
[41] Jaeger, L. and A. Eckhardt, "When Colleagues Fail: Examining the Role of Information Security Awareness on Extra-Role Security Behaviors", in 26th European Conference on Information Systems: Beyond Digitization - Facets of Socio-Technical Change, P.M. Bednar, U. Frank, and K. Kautz, Editors, European Conference on Information Systems, Portsmouth, UK, June 23-28, 2018. 2018.

[42] Kahn, W.A., "Psychological Conditions of Personal Engagement and Disengagement at Work", Academy of Management Journal, 33(4), 1990, pp. 692-724.

[43] Lee, M.K.O., C.M.K. Cheung, and Z. Chen, "Acceptance of Internet-based learning medium: the role of extrinsic and intrinsic motivation", Information \& Management, 42(8), 2005, pp. 1095-1104.

[44] Lin, H.-F., "Effects of extrinsic and intrinsic motivation on employee knowledge sharing intentions", Journal of Information Science, 33(2), 2007, pp. 135-149.

[45] Lowry, P.B., J. D’Arcy, B. Hammer, and G.D. Moody, "Cargo Cult" science in traditional organization and information systems survey research: A case for using nontraditional methods of data collection, including Mechanical Turk and online panels", The Journal of Strategic Information Systems, 25(3), 2016, pp. 232-240.

[46] Maccoby, E.E., "Gender and Relationships: A Developmental Account", American Psychologist, 1990, pp. 514-520.

[47] MacKenzie, S.B. and P.M. Podsakoff, "Common Method Bias in Marketing: Causes, Mechanisms, and Procedural Remedies", Journal of Retailing, 88(4), 2012, pp. 542-555.

[48] Matzler, K., B. Renzl, J. Müller, S. Herting, and T.A. Mooradian, "Personality traits and knowledge sharing", Journal of Economic Psychology, 29(3), 2008, pp. 301-313.

[49] McCormac, A., T. Zwaans, K. Parsons, D. Calic, M. Butavicius, and M. Pattinson, "Individual differences and Information Security Awareness", Computers in Human Behavior, 69, 2017, pp. 151-156.

[50] McGill, T. and N. Thompson, "Gender Differences in Information Security Perceptions and Behaviour", in Proceedings of the 29th Australasian Conference on Information Systems, Sydney, Australia. 2018.

[51] Menard, P., G.J. Bott, and R.E. Crossler, "User Motivations in Protecting Information Security: Protection Motivation Theory Versus Self-Determination Theory", Journal of Management Information Systems, 34(4), 2017, pp. 1203-1230.

[52] Michailova, S. and K. Husted, "Knowledge-Sharing Hostility in Russian Firms", California Management Review, 45(3), 2003, pp. 59-77.

[53] Miller, D.L. and L. Karakowsky, "Gender influences as an impediment to knowledge sharing: when men and women fail to seek peer feedback", The Journal of Psychology, 139(2), 2005, pp. 101-118. 
[54] Norrick, N.R., "Narratives of vicarious experience in conversation", Language in Society, 42(04), 2013, pp. 385406.

[55] Owens, J. and E.M. Hawkins, "Using Online Labor Market Participants for Nonprofessional Investor Research: A Comparison of MTurk and Qualtrics Samples", Journal of Information Systems, 33(1), 2019, pp. 113-128.

[56] Paroutis, S. and A. Al Saleh, "Determinants of knowledge sharing using Web 2.0 technologies", Journal of Knowledge Management, 13(4), 2009, pp. 52-63.

[57] Ponemon Institute, Cost of a Data Breach Report, Ponemon Institute, 2019.

[58] Puhakainen, P. and M. Siponen, "Improving Employees' Compliance Through Information Systems Security Training: An Action Research Study", MIS Quarterly, 34(4), 2010, pp. 757-778.

[59] Qiu, L. and S. Kumar, "Understanding Voluntary Knowledge Provision and Content Contribution Through a Social-Media-Based Prediction Market: A Field Experiment", Information Systems Research, 28(3), 2017, pp. 529-546.

[60] Rocha Flores, W. and M. Ekstedt, "Shaping intention to resist social engineering through transformational leadership, information security culture and awareness", Computers \& Security, 59, 2016, pp. 26-44.

[61] Safa, N.S. and C. Maple, "Human errors in the information security realm - and how to fix them", Computer Fraud \& Security(9), 2016, pp. 17-20.

[62] Safa, N.S., C. Maple, T. Watson, and R. von Solms, "Motivation and opportunity based model to reduce information security insider threats in organisations", Journal of Information Security and Applications, 40, 2018, pp. $247-$ 257.

[63] Safa, N.S. and R. von Solms, "An information security knowledge sharing model in organizations", Computers in Human Behavior, 57, 2016, pp. 442-451.

[64] Shropshire, J., M. Warkentin, and S. Sharma, "Personality, attitudes, and intentions: Predicting initial adoption of information security behavior", Computers \& Security, 49, 2015, pp. 177-191.

[65] Siponen, M.T., "A conceptual foundation for organizational information security awareness", Information Management \& Computer Security, 8(1), 2000, pp. 31-41.

[66] Sitkin, S.B., "Learning through failure: The strategy of small losses", Research in Organizational Behaviour, 14, 1992, pp. 231-266.

[67] Tatu, T., C. Ament, and L. Jaeger, "Lessons Learned from an Information Security Incident: A Practical Recommendation to Involve Employees in Information Security", in 51st Hawaii International Conference on System Sciences, T. Bui, Editor, HICSS. 2018.

[68] Tsohou, A., M. Karyda, and S. Kokolakis, "Analyzing the role of cognitive and cultural biases in the internalization of information security policies: Recommendations for information security awareness programs", Computers \& Security, 52, 2015, pp. 128-141.

[69] Uffen, J., N. Guhr, and M.H. Breitner, "Personality Traits and Information Security Management: An Empirical Study of Information Security Executives", Proceedings of the International Conference on Information Systems, Orlando, Florida, USA, 2012.

[70] Vallerand, R.J., "Deci and Ryan's Self-Determination Theory: A View from the Hierarchical Model of Intrinsic and Extrinsic Motivation", Psychological Inquiry, 11(4), 2000, pp. 312-318.

[71] Volz, E., Consumer Alert: Warwick woman warns of fake Microsoft IT scam, NBC 10 News, 2018.

[72] Wasko, M.M. and S. Faraj, "Why Should I Share? Examining Social Capital and Knowledge Contribution in Electronic Networks of Practice", MIS Quarterly, 29(1), 2005, pp. 35-57.

[73] Williams, B., A. Onsman, and T. Brown, "Exploratory factor analysis: A five-step guide for novices", Journal of Emergency Primary Health Care, 8(3), 2010.

[74] Wilson, M. and J. Hash, Building an Information Technology Security Awareness and Training Program, National Institute of Standards and Technology, 2003.

[75] Zhao, L., B. Detlor, and C.E. Connelly, "Sharing Knowledge in Social Q\&A Sites: The Unintended Consequences of Extrinsic Motivation", Journal of Management Information Systems, 33(1), 2016, pp. 70-100.

[76] Zindler, A. and C. Bolz, Digitalbarometer: Digitalbarometer: Bürgerbefragung zur Cyber-Sicherheit, Federal Office for Information Security (BSI) and Police Crime Prevention of the States and the Federal Government (ProPK), 2020. 